\title{
Profilierter Vertreter der Allgemeinen Pädagogik: Klaus Prange (1939-2019)
}

\author{
Markus Rieger-Ladich
}

Am 29. Juni 2019 ist Professor Dr. Klaus Prange im Alter von 8o Jahren gestorben. Mit ihm verliert die Erziehungswissenschaft einen ihrer originellsten und profiliertesten Vertreter. In seiner Tübinger Zeit prägte er nicht nur den Fachdiskurs und legte viel diskutierte Arbeiten vor; er entwickelte mit seiner »Operativen Pädagogik« zudem eine höchst eigenständige Theorie der Erziehung, die bis heute intensiv rezipiert wird.

Im Anschluss an das Studium der Fächer Deutsch, Englisch, Philosophie und Pädagogik unterrichtete Klaus Prange von 1964 bis 1972 als Gymnasiallehrer. Er promovierte in dieser Zeit mit einer philosophischen Arbeit an der Universität Kiel und habilitierte sich mit einer Studie zur Pädagogik als Erfahrungsprozess (1975). Kurz darauf erhielt er einen Ruf an die Universität Kiel und lehrte dort bis 1985 Allgemeine Pädagogik. Nach einem Wechsel an die Universität Bayreuth, wo er von 1985 bis 1989 tätig war, bekleidete er den Lehrstuhl für Allgemeine Pädagogik an der Universität Tübingen. Er stand für einige Jahre dem Institut für Erziehungswissenschaft als Direktor vor und engagierte sich in den Kommissionen Bildungs- und Erziehungsphilosophie sowie Wissenschaftsforschung der Deutschen Gesellschaft für Erziehungswissenschaft wie auch in der Herbart-Gesellschaft. Nach seiner Emeritierung an der Eberhard Karls Universität war er als Honorarprofessor an der Universität Oldenburg tätig.

Klaus Prange war einer der originellsten Vertreter der Allgemeinen Pädagogik. Er entwickelte sein intellektuelles Profil in der Auseinandersetzung mit den Eigentümlichkeiten des pädagogischen Denkstils. Nachdem er zunächst mehrere Studien zum Begriff der Erfahrung vorgelegt und »Bauformen des Unterrichts« (1983) identifiziert hatte, befasste er sich mit der Anthroposophie Rudolf Steiners und der pädagogischen Praxis, die daraus abgeleitet wurde. Seine scharfe Kritik der Waldorfpädagogik, die mehrere Auflagen erlebte, ist bestechend und hat kaum etwas von ihrer Gültigkeit eingebüßt. Von dem Widerspruch, den er erntete, ließ er sich nicht beirren und legte wenige Jahre darauf eine Arbeit zu Rudolf Steiners Bild des Kindes vor. 
Nach einzelnen Beiträgen zum Problem der Lehrbarkeit der Erziehung veröffentlichte Prange 2005 »Die Zeigestruktur der Erziehung«. Hier entwickelte er die systematischen Grundlagen seines Entwurfs einer »Operativen Pädagogik«. Statt sich noch länger über den Begriff der Bildung zu profilieren und von dessen Aura zu profitieren, sei die Erziehungswissenschaft gehalten, endlich jenen Begriff genauer auszuarbeiten, den sie im Titel trage - so seine treffende Kritik. Geschult an den Arbeiten Herbarts und inspiriert von der soziologischen Systemtheorie sowie der Wissenschaftstheorie der Erlanger Schule, entwickelte er seine Theorie der Erziehung. Der Keim des Pädagogischen liege in jener Geste des Zeigens, die mit der Absicht, einen Lernprozess auszulösen, auf ein Objekt oder einen Sachverhalt hinweist. Erziehung wird damit als anspruchsvolle Tätigkeit entworfen, der es obliegt, Zeigen und Lernen zu koordinieren. Bald darauf machte er in »Ethik der Pädagogik« (2010) die normativen Fragen zum Gegenstand, die damit virulent werden. Erziehung ist, das räumte Prange ein, beileibe keine >reine Kategorieく; sie ist stets eingelagert in soziale und gesellschaftliche Kontexte.

Was Pranges »Operative Pädagogik« kennzeichnet, gilt auch für seine übrigen Arbeiten: Die Theorie des Zeigens besticht durch das Bemühen um größtmögliche sprachliche Genauigkeit und argumentative Kohärenz. Dieses Ethos der Sachlichkeit ist gepaart mit einem distanzierten Blick auf die Usancen des wissenschaftlichen Feldes und einer ausgeprägten Lust an der Auseinandersetzung. Prange besaß ein feines Gespür für die Untiefen des pädagogischen Denkstils und nicht zuletzt auf den Versuch, argumentative Unzulänglichkeiten durch moralisches Engagement zu kompensieren, reagierte er allergisch. Es gibt, so seine nüchterne Auskunft, in pädagogischen Kontexten >keine Unschuld $<$ und allen Formen der Bemäntelung dieses Sachverhalts trat er mit der gebotenen Schärfe entgegen. Immer wieder ging er mit der Disziplin streng ins Gericht, schonte dabei niemanden - aber hatte doch stets die Weiterentwicklung einer Reflexionskultur vor Augen, die sich an dem orientiert, was Siegfried Bernfeld seinerzeit `Tatbestandsgesinnungく genannt hatte.

Dass Prange seine stupende Gelehrsamkeit stets in den Dienst der Sache stellte, wurde noch einmal deutlich in den beiden Bänden »Schlüsselwerke der Pädagogik « (2008). Er stellte hier Werkporträts zusammen und diskutierte zentrale Texte des Abendlandes. Seine knappen Beiträge sind von einer unerhörten Prägnanz und Klarheit. Ohne falschen Respekt erläuterte er Texte von Platon, Hegel und Dewey und macht sie auf diese Weise (nicht nur) Studierenden zugänglich. Und auch hier, in diesen brillanten Porträts, blitzt immer wieder der trockene Humor ihres Verfassers auf. 
Klaus Prange war mit den Paradoxien des Pädagogischen sehr vertraut und hat sie selbst immer wieder zum Gegenstand gemacht. Mit ihm verliert die Disziplin einen der schärfsten Kritiker - und zugleich einen ihrer profiliertesten Vertreter. 